\title{
The nucleate boiling in a droplet of aqueous salt solution
}

\author{
Sergey Misyura ${ }^{1,2, *}$ Anton Meleshkin ${ }^{1,2}$ \\ ${ }^{1}$ Kutateladze Institute of Thermophysics of the Siberian Branch of the Russian Academy of Sciences, 1. Lavrentiev Ave., \\ Novosibirsk, 630090, Russia \\ ${ }^{2}$ Novosibirsk State University, 2 Pirogova Street, 630090 Novosibisk, Russia
}

\begin{abstract}
This paper is devoted to an experimental study of the dynamics of the nucleate boiling in a droplet of aqueous solution of $\mathrm{LiBr}$ salt. As the concentration of $\mathrm{LiBr}$ salt increases, the growth rate of the bubbles decreases and the boiling completely stops when a high salt concentration is reached. An increase in the concentration of salt in the liquid layer of the bottom of the bubble leads to a decrease in the rate of increase in the diameter of the bubble, and a dry spot is not formed. The growth rate of a bubble $(v)$ in a water droplet is somewhat higher than one for a salt solution for $t>0.2-0.3 \mathrm{~s}$. The difference of $v$ for the salt solution from curve 3 increases sharply when $t<0.1 \mathrm{~s}$. For the first time, four regimes of the nucleate boiling in $\mathrm{LiBr}$ solution droplet were detected.
\end{abstract}

\section{Introduction}

The evaporation processes are widely used in practice [1-3] and are often observed in nature, medicine and biology. Evaporation of a drop and liquids were studied in [4-10]. In the presence of intense nucleation boiling in a drop, the wetting diameter for distilled water first increases by more than two times, and then both the diameter and the contact angle decrease continuously. The evaporation of droplets leads to a decrease in a combustion temperature and an efficiency of combustion technologies for gas hydrates [11-15]. When nucleate boiling, it is important to know the number of active nucleation centers and their spatial and temporal distribution. It is important to know the dependencies for the rate of bubble growth. The dynamics of evaporation depend on wettability and droplet diameter $[1,2,4,9,16]$. In technologies, not pure liquids are often used but solutions. Vapor absorption is used in absorbers, and vapor evaporation is carried out in desorbers of lithium-bromide heat pumps. The evaporation behavior of saline solutions and crystallization were studied experimentally in $[17,18]$. The process of absorption in salt solution was investigated theoretically in [19]. The combined influence of the evaporation, heat transfer and crystallization was considered in $[20,21]$. The rate of evaporation depends strongly on a degree of turbulence, free convection in gas and liquid [22]. The method for measuring the velocity field in a drop using PIV method is presented in [23].

The purpose of this paper is an experimental study of the growth dynamics of a vapor bubble in salt solution.

\section{Experimental method and analysis}

The experiments were carried out on a horizontal heated titan wall (Figure 1). Ambient air temperature was $24{ }^{\circ} \mathrm{C}$ and ambient air pressure was $1 \mathrm{~atm}$. The diameter of the working surface (working heater) was $60 \mathrm{~mm}$. The wall temperature $\left(T_{w}\right)$ was kept constant in automatic mode with an accuracy of $1{ }^{\circ} \mathrm{C}$ and equal to $140{ }^{\circ} \mathrm{C}$ (before placing the droplet on the heated wall). The initial mass concentration of the aqueous salt solution of $\operatorname{LiBr}\left(C_{0}\right)$ was $30 \%$ and was determined by standard densitometers. Current salt concentration $C_{1}$ of the salt solutions was determined by a weight method. The setup was placed on the accurate balance (5). As the salt concentration grows with time, the water concentration, on the contrary, decreases over time $\left(C_{2}=C_{\mathrm{H}_{2} \mathrm{O}}=1-C_{1}\right.$; where $C_{\mathrm{H}_{2} \mathrm{O}}=m_{\mathrm{H}_{2} \mathrm{O}} / \mathrm{m} ; C_{1}=C_{\text {sol }}=m_{\text {sol }} / \mathrm{m} ; \mathrm{m}_{\mathrm{H}_{2} \mathrm{O}}$, $m_{\text {sol }}, m\left(m=m_{\mathrm{H}_{2} \mathrm{O}}+m_{\text {sol }}\right)$ are the mass of water, salt and aqueous salt solution. The temperature $\left(T_{s}\right)$ of the droplet surface was measured by the thermal imager (NEC-San Instruments, $640 \times 512$ pixels). The temperature $\left(T_{w}\right)$ of the wall surface of the heater was determined by thermocouples located near the wall with a relative error within $1 \%$. The error of thermal imaging measurements associated with a change in salt concentration from 10\% to 60-65\% was 1$2 \%$. Liquid droplets were formed by a dispenser with a maximum relative error of $0.5 \%$. The droplet placement was realized without the decay of the droplet, since the distance of the dispenser from the wall surface was $6 \mathrm{~mm}$.

*Corresponding author: misura@itp.nsc.ru 


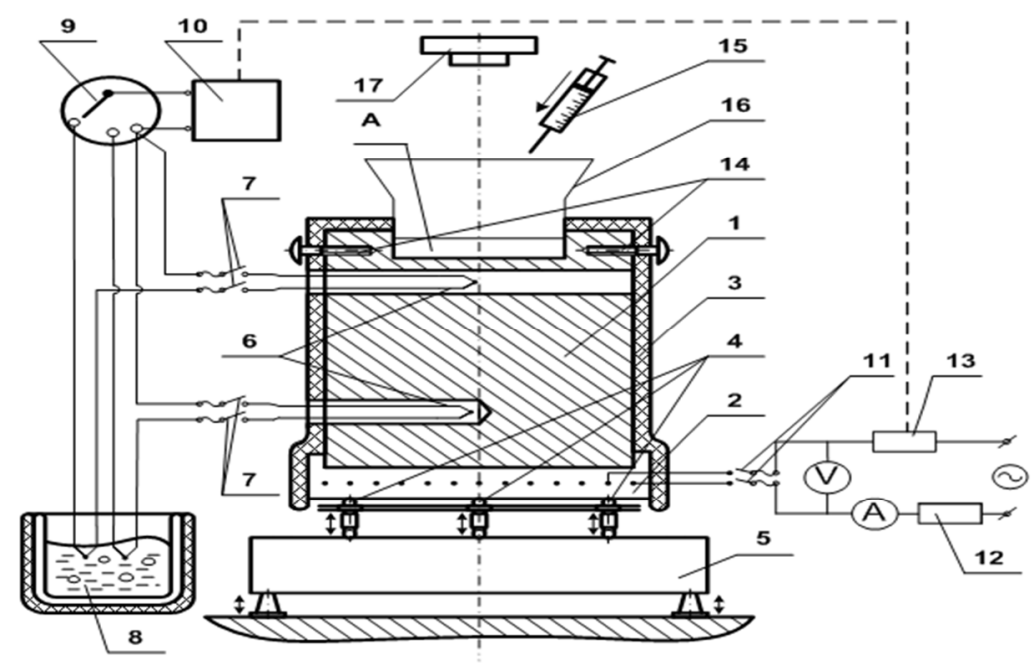

Fig. 1. Scheme of setup: A - working heating surface; 1 - titanium cylinder; 2 - electric heater; 3 - multilayer screen thermal insulation; 4 - adjustable supports; 5 - analytical balance; 6 - thermocouples; 7 - flexible detachable element of thermocouple; 8 Dewar vessel with ice; 9 - thermocouple switch; 10 - millivoltmeter; 11 - flexible detachable element of electric wiring; 12 laboratory thermotrnasformer; 13 - temperature regulator; V and $\mathrm{A}$ - voltmeter and ammeter; 14 - puller ear; 15 - metering device; 16 - protecting screen; 17 - video camera, thermal imager.

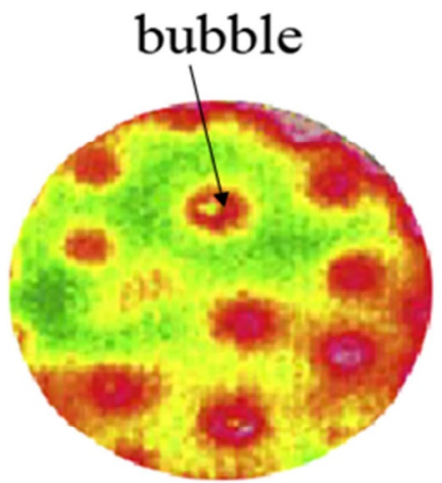

$3 \mathrm{~s}$

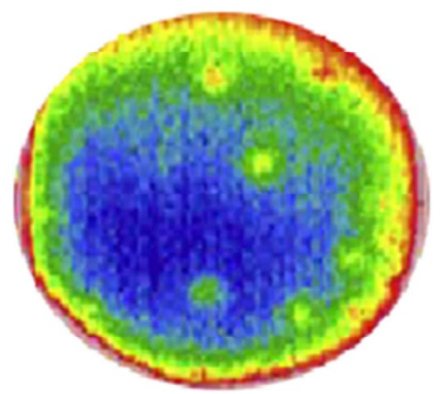

$9 \mathrm{~s}$

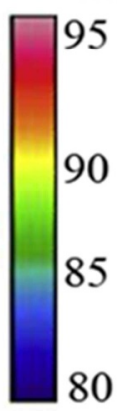

${ }^{0} \mathrm{C}$

Fig. 2. Thermal images of nucleate boiling of the $\mathrm{H}_{2} \mathrm{O} / \mathrm{LiBr}$ droplet $\left(C_{0}=30 \% ; T_{w}=140{ }^{\circ} \mathrm{C} ; V_{0}=150 \mu \mathrm{l}\right)$.

Figure 2 shows the temperature measurements on the droplet surface $\left(\mathrm{H}_{2} \mathrm{O} / \mathrm{LiBr}\right)$ using the thermal image. The nucleate boiling is implemented in the droplet. There is a significant temperature gradient along the droplet diameter. The bottom of the bubble (the bubble is shown by the arrow $(t=3 \mathrm{~s})$ ) is completely covered with a thin film of the liquid solution without a dry spot (the dry spot occurs when the wall surface is not wetted with liquid). If there was a dry spot on the surface of the metal, then the thermal images would show this area in black, because the emission coefficient of the metal was low $k$ ( $k$ much less than 1$)$. In pure water for bubbles with a diameter of more than $1 \mathrm{~mm}$, there is always a dry spot of the bubble bottom. The maximum concentration of LiBr salt is in the center of the bubble bottom. After destruction of a thin film (bubble blast) located at the bubble top, the liquid flows to the thin layer and reduces the temperature and the salt concentration near the bubble center. As can be seen from Fig. 2, the nucleate boiling degenerates $(t=9 \mathrm{~s})$ with increasing salt concentration. The thermodynamic equilibrium of the salt solution shifts with increasing evaporation time.

The rate of the bubble growth is shown in Fig. 3(a) ( $v=\Delta D / \Delta t$, where $D$ is the bubble diameter, $t$ is time, $\Delta T$ is the overheating relative the boiling point $\left(100{ }^{\circ} \mathrm{C}\right.$ for water $\left.)\right)$. The growth rate of the diameter decreases with time, that corresponds to the solution of the Rayleigh equation. The rate $v$ in aqueous salt solution (curve 1) is slightly less than in water (curve 2). Dependence (3) for bubble radius $R$ (Fig. 3(b)) corresponds to expression (1) [24].

$$
R=\sqrt{\frac{2 \beta \lambda \Delta T t}{r \rho_{v}}}
$$




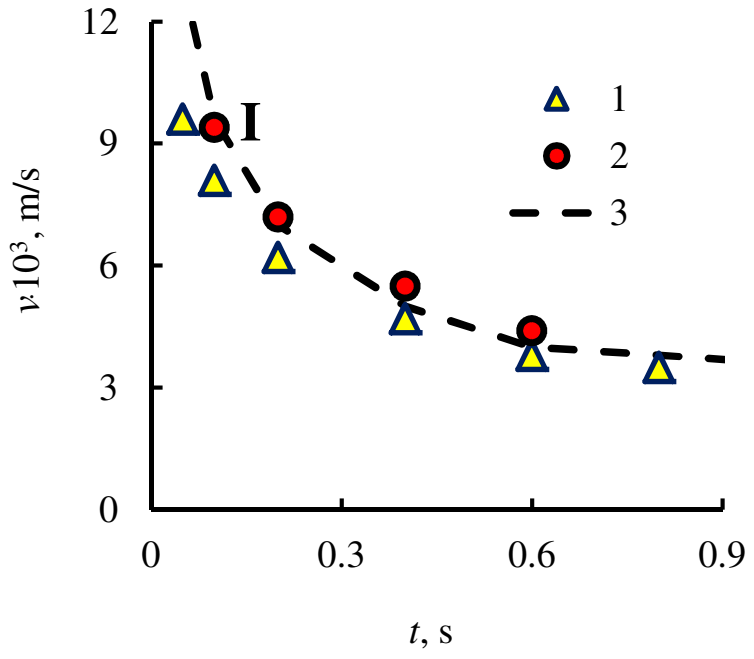

(a)

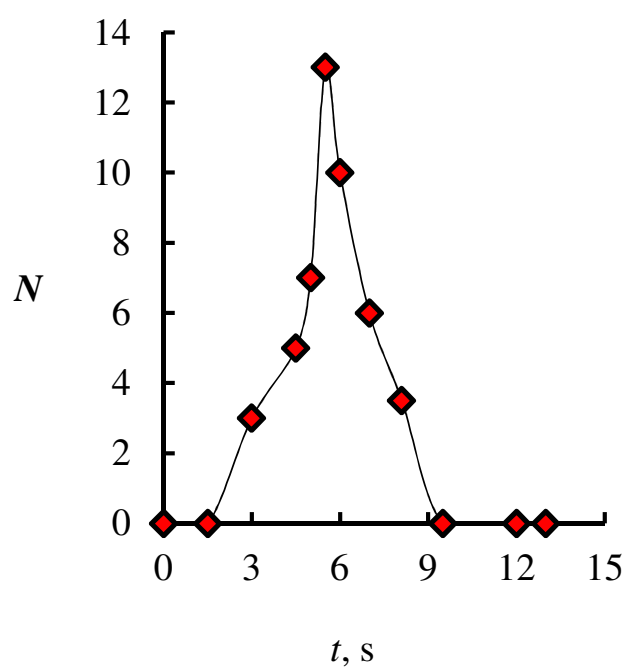

(b)

Fig. 3. a) The rate of the bubble diameter growth with time $(v=\Delta D / \Delta t)$ : curve $1-\operatorname{LiBr}$ solution $\left(C_{0}=30 \% ; \Delta T=13{ }^{\circ} \mathrm{C}\right) ; 2-$ water $\left(\Delta T=13{ }^{\circ} \mathrm{C}\right) ; 3$ - for water by $(1)\left(\Delta T=10^{\circ} \mathrm{C}\right)$; b) The change in the number of vapor bubbles in a droplet of LiBr salt solution $\left(C_{0}=15 \% ; T_{w}=135^{\circ} \mathrm{C}\right)$. $\mathbf{I}$ is the interval of measurement errors

The difference of $v$ from curve 3 increases sharply when $t<0.1 \mathrm{~s}$. Perhaps the high growth rate of the bubble in the droplet salt solution is associated with the solutal Marangoni number in a surface of a thin bubble layer near a contact line of the bubble. A change in the number of bubbles $N$ in the droplet vs. time is shown in Fig. 3(b). There are several modes for changing $N: 1$ ) the absence of boiling due to warming up the liquid; 2) the intense boiling; 3) a degeneration of boiling; 4) the evaporation without boiling due to the growth of the salt concentration.

\section{Conclusions}

The experimental study for the dynamics of the nucleate boiling in a sessile droplet of aqueous solution of $\mathrm{LiBr}$ salt and water were conducted.

As the concentration of $\mathrm{LiBr}$ salt increases, the growth rate $v$ of the bubble decreases and the boiling completely stops when a high salt concentration is reached. The growth rate $v$ in aqueous salt solution is slightly less than in water. The difference of $v$ from Labuntsov curve increases sharply when $t<0.1 \mathrm{~s}$.

The bottom of the bubble is completely covered with a thin film of the liquid solution without a dry spot. The absence of the dry spot will lead to an increase in the critical heat flux (a shift in the boiling crisis toward higher temperatures).

The nucleate boiling degenerates with increasing salt concentration. The thermodynamic equilibrium of the salt solution shifts with increasing evaporation time. For the first time, four regimes of the nucleate boiling in $\mathrm{LiBr}$ solution droplet were detected.

Experiments were carried out at the Kutateladze Institute of Thermophysics of the Siberian Branch of the Russian Academy of Sciences. This work was supported by grants of Russian Science Foundation (Project № 15-19-10025).

\section{References}

1. G.V. Kuznetsov et. al., Thermophysics and Aeromechanics 23, 17 (2016)

2. G.V. Kuznetsov et. al., J. of Engineering Thermophysics 89, 317 (2016)

3. S.Y. Misyura, Exp. Therm. Fluid Sci. 84, 190 (2017)

4. V.E. Nakoryakov et al., Doklady Physics 59, 441 (2014)

5. G.V. Kuznetsov et. al., Int. J. Heat Mass Transfer 96, 20 (2016)

6. P.A. Strizhak et. al., J. of Hazardous Materials 338, 148 (2017)

7. S.Y. Misyura, Scientific Reports 7, 14759 (2017)

8. V.V. Kuznetsov et al., J. Eng. Thermophys. 24, 357 (2015)

9. V.E. Nakoryakov et. al., J. of Engineering Thermophysics 25, 24 (2016)

10. S.Y. Misyura, Exp. Therm. Fluid Sci. 75, 43 (2016)

11. S.Y. Misyura, I.G. Donskoy, Chem. Eng. Sci. 148, 65 (2016)

12. S.Y. Misyura, V.E. Nakoryakov, Energy and Fuels 27, 7089 (2013)

13. M.E. Semenov et. all., Journal of Thermal Analysis and Calorimetry 119, 757 (2015)

14. S.Y. Misyura, Energy 103, 430 (2016) 
15. V.E. Nakoryakov et. al., J. of Engineering Thermophysics 22, 169 (2013)

16. S.Y. Misyura, Applied Thermal Engineering 113, 472 (2017)

17. S.Y. Misyura, Appl. Therm. Eng. 139, 203 (2018)

18. S.Y. Misyura, Crystal Growth and Design 18, 1327 (2018)

19. V.E. Nakoryakov, N.I. Grigoryeva, Novosibirsk, Nauka, 2010

20. S.Y. Misyura, Chem. Eng. Research and Design 126, 153 (2017)

21. F. Carle et al., Intern. J. of Therm. Sci. 101, 35 (2016)

22. V.P. Lebedev et. al., Fluid dynamics 28, 624 (1993)

23. G.V. Kuznetsov et. al., Appl. Therm. Eng. 131, 340 (2018)

24. D.A. Labuntsov, J. Eng. Phys. Thermophys. 6, 33 (1963). 